\title{
Negative Emotions and Coping Behaviors of Passenger in the Airline Industry, Vietnam
}

\author{
Canh Chi HOANG ${ }^{1}$
}

Received: August 01, 2020 Revised: September 06, 2020 Accepted: September 10, 2020

\begin{abstract}
In Vietnam, the airline service sector plays an important economic role. However, it is a complicated industry that is open to failures. Negative emotions are an essential variable for the airline service industry because they can trigger a variety of coping behaviors that affect consumer loyalty as well as the image and reputation of the airline service providers. However, negative emotions and the accompanying coping behaviors are often investigated partially or as separate issues, thus leading to an incomplete understanding. This study is conducted to fill this gap by proposing and testing the causal relationship between negative emotions (anger, frustration, regret) and coping behaviors (complaint, negative word-of-mouth (WOM), and switching intention) in the context of the airline industry. Eight research hypotheses are tested. Using the partial least squares structural equation modeling (PLS-SEM) on a sample of 587 passengers in Vietnam, the empirical results show that anger and frustration influence complaints, negative WOM, and switching intention, while regret leads to switching intention and negative WOM. Thus, the research has important academic and practical implications. The empirical outcome could be of major importance for airline companies in planning to provide new services and achieve high performance in the long run.
\end{abstract}

Keywords: Negative Emotion, Coping Behavior, Complaints, WOM, Switching Intention

JEL Classification Code: D03, D11, L93, M31, R40

\section{Introduction}

According to the International Air Transport Association (IATA), Vietnam is in the top 10 countries with the highest growth rate of airlines (only direct flights) in the world. The average growth was $32.65 \%$ from 2011 to 2017. Accordingly, in 2019, passenger transport increased by $9.4 \%$ compared to 2018 and reached 38.5 million passengers. Notably, the rate of flight cancellation and flight delays increased by $1.5 \%$ and $2.6 \%$, respectively, over the same period in 2018.

In Vietnam, the services sector plays an important role, with the contribution ratio of the services industry accounting

${ }^{1}$ First Author and Corresponding Author. Faculty of Business Administration, University of Finance - Marketing, Ho Chi Minh City, Vietnam [Postal Address: 2 Tran Xuan Soan Street, District 7, Ho Chi Minh City 700000, Vietnam]

Email: canhchihoang@ufm.edu.vn

(c) Copyright: The Author(s)

This is an Open Access article distributed under the terms of the Creative Commons Attribution Non-Commercial License (https://creativecommons.org/licenses/by-nc/4.0/) which permits unrestricted non-commercial use, distribution, and reproduction in any medium, provided the original work is properly cited. between $24 \%$ to $43 \%$ of GDP. The service sector and the airline service industry, in particular, provide invisible and complicated services (Hoang \& Ngoc, 2019). These services are hard to stabilize and inseparable with a service provider (Gao \& Kerstetter, 2018; Susskind, 2016; Khoa, 2020). In business activities, service failures, or failures in the provision of the service are entirely inevitable, which leads to the formation of negative emotions of customers. Based on responsible objects (Stephens \& Gwinner, 1998) and the Cognitive Appraisal Theory (Folkman et al., 1986), previous empirical studies indicate that failure to provide services will form a sense of anger, frustration, and regrets (Laros \& Steenkamp, 2005; Roseman, 1991; Zeelenberg \& Pieters, 2004). These different emotions are an individual response of the customer to various errors of service providers, namely, anger tends to appear when the customer thinks that the cause of stress occurs due to the faults of the particular external object (e.g., airplane); frustration is attributed to the customer who is responsible for the uncontrollable situation factors; and regrets is expressed when customer thinks that the faults are their own (Bonifield \& Cole, 2007). To minimize negative emotions and increase comfort, consumers will perform typical coping behaviors such as 
complaints, sharing of negative experiences, and switching intention (Lazarus, 1991; Watson \& Spence, 2007).

The previous studies have performed a link analysis between anger and frustration with coping behaviors (Bonifield \& Cole, 2007; Bougie et al., 2003). However, the effects of regrets are not much explored. Moreover, a consumer can form different negative emotions from bitter experiences, and meanwhile, the simultaneous impact of these three types of negative emotions to counteracts is still unclear because the consumer can perform multiple coping behaviors (Mattila \& Ro, 2008; Stephens \& Gwinner, 1998). Besides, studies often deal with coping behaviors in the context of the failure of a service provider in a separate approach (Mattila \& Ro, 2008; Ro, 2014), while recent studies indicate the need for simultaneous viewing of coping behaviors to investigate the response of customer when dissatisfied (Gao \& Kerstetter, 2018; Susskind, 2016). The main contribution of this research is as follows: first, the study investigates the different impacts of the three types of negative emotions on the behavior of the consumer; second, the research, not only considers every kind of separate coping behaviors, but simultaneously investigates three types of coping behaviors. Therefore, the research brings a deeper understanding of consumer behavior in stressful situations.

\section{Literature Review}

\subsection{The Cognitive Appraisal Theory}

The Cognitive Appraisal Theory can be seen as "a process of judging the significance of an event for personal wellbeing" (Folkman et al., 1986). An incident, if influencing personal resources and jeopardizing happiness, can lead to psychological stress (Donoghue \& De Klerk, 2013; Gao \& Kerstetter, 2018; Han, 2020). To arouse an emotion, an event must be appraised as affecting a person in some way (Bougie et al., 2003). The appraisal is a two-step process as follows: (i) the first step is when an individual who determines whether the occurrence is harmful or dangerous to itself, the outcome of this step is basic emotions and reacts with harm or benefit; (ii) the second step is the complex evaluation process that measures the deal options, the likelihood that coping behaviors have helped them achieve what they desire, and the ability to use one or some effective coping behaviors.

\subsection{A Summary of Experimental Studies}

\subsubsection{The Customer's Coping Strategy for the Failure of the Airline Service Provider}

Coping is the process where individuals judge the needs (inside or outside) that are formed from the stressful relationship between the individual and the environment, and the various emotions that their demand generates (Stephens \& Gwinner, 1998). The failure in providing airline service is considered a situation that triggers stress in the relationship between passenger and airline companies (Ro, 2014). Therefore, the strategic solution for the failure in providing airline service is the cognitive and emotional efforts of the passenger to judge the needs by themselves in these situations (Mathur et al., 1999).

Lazarus and Folkman (1984) discover the two types of coping behaviors are: (1) coping with the focus on events or towards judging and altering the events of causing stress; (2) dealing with emotional focus or towards regulating emotional responses to events. The third type of coping behavior is avoidance, proposed by Mathur and Associates (1999), Stephens and Gwinner (1998). It implies that passengers can leave stressful situations and switch to the service of other airline companies (Bagozzi et al., 2002). Whether passengers can choose various coping behaviors, they also need to know who is responsible for stressful situations, and their coping behavior will be directed to that subjects (Mathur et al., 1999; Watson \& Spence, 2007, Nguyen \& Khoa, 2019). For example, the passenger will use a strategy focusing on the events (e.g., complaints) when determining who is responsible as third parties (e.g., staff, manager) (Stephens \& Gwinner, 1998). Contrary to the events-focused strategies, emotional focus-focused strategy (e.g., negative WOM) often blame themselves, and therefore, passengers will share this dissatisfaction experience with their family, friends, or colleagues to dispel feelings of frustration or discouragement (Lazarus \& Folkman, 1984). Finally, for the strategy focuses on avoidance, passengers can choose for silent retreats and form intentions to switch to other companies due to the thought that trying to resolve the situation will only take the time and effort (Stephens \& Gwinner, 1998).

Previous studies suggest that coping behaviors would have a connection with one of the three above-mentioned strategies (Donoghue \& de Klerk, 2013; Watson \& Spence, 2007). Furthermore, empirical results also show that customers can develop multiple coping behaviors that belong to different situations when they want to control stressful situations (Gao \& Kerstetter, 2018; Susskind, 2016). In the context of the failure in the service industry, previous studies have often considered partially or separately coping behavior (Mattila \& Ro, 2008; Ro, 2014), while the simultaneous consideration of coping behaviors is necessary to be able to deepen the understanding of the response of customer when they do not feel satisfied.

This study focuses on three types of coping behaviors, including complaint (strategic focus on problems), negative WOM (strategic focus on emotion), and switching intention (strategy focus of avoidance) (Mattila \& Ro, 2008; Stephens \& Gwinner, 1998). A complaint is the first communication of the customer with the service provider 
to achieve a corrective solution for the dissatisfaction events (Swan \& Oliver, 1989). Negative WOM implies that customers will talk with colleagues and acquaintances about negative experiences and encouraging them not to use the service of this provider (Zeithaml et al., 1996). The switching intention implies that customers will stop dealing with the current service provider and switch to using the service of other providers (Oliver, 2014).

\subsubsection{Negative Emotions and Coping Behaviors}

According to the Cognitive Appraisal Theory (Folkman et al., 1986), coping behaviors are a result of the preliminary negative emotions reacting to situations that negatively affect personal well-being and resources. In other words, the specific emotions are a result of the combination of events/situations and the ability to come up with solutions (Lazarus, 1991). Moreover, negative emotions often appear when there is a failure in the provision of services, and it implies that customer needs coping behaviors (Mattila \& Ro, 2008). The relationship between specific emotions and coping behaviors is complicated (Mattila \& Ro, 2008). To understand the coping behaviors, it is necessary to have a thorough knowledge of the role of the emotional experiences and responses of the customer in the context of failure in providing services (Lazarus, 1991).

The failure in providing products/services often creates characteristic negative emotions, and these feelings contribute to deciding on the implementation of the next acts (Mattila \& Ro, 2008). These behaviors are often countermeasures taken by individuals always to seek ways to minimize unpleasant sensations as well as increase their beneficial feelings (Lazarus, 1991). Previous studies indicate that specific emotions such as anger and regret will increase the dissatisfaction of customers (Mano \& Oliver, 1993; Smith \& Bolton, 2002). Similarly, anger and frustration are the direct results of the failures in providing service (Laros $\&$ Steenkamp, 2005). Anger, frustration, and regret are the real emotions of customers, and these emotions trigger their coping behavior (Donoghue \& De Klerk, 2013; Ro, 2014). However, these negative emotions are rarely considered at the same time in the airline service sector. Therefore, this study investigates the impact of three negative emotions (anger, frustration, regret) on coping behaviors of passengers (complaint, negative WOM, and switching intention).

Anger and frustration are emotionally reimagined and appear when a passenger assigns a specific event that does not conform to their goal to an external object (e.g., planes, staff) (Donoghue \& de Klerk, 2013; Gelbrich, 2009; Roseman, 1991). Anger is considered a significant emotion in marketing and emotion literature (Kalamas et al., 2008). Previous studies confirm that negative emotions have a positive impact on consumer retaliation (Grégoire \& Fisher, 2008; Tronvoll,
2011; Zourrig et al., 2009). For example, according to Bougie et al. (2003), anger motivates consumers to complain and share bitter experiences (negative WOM), while Bonifield and Cole (2007) show that an increase in anger leads to an increase in switching intention. Furthermore, the Cognitive Appraisal Theory also indicates that negative emotions affect coping behavior in the service sector. Therefore, this study proposed the following hypotheses:

\section{$\boldsymbol{H}_{1 a}:$ Anger has a positive impact on the complaint \\ $\boldsymbol{H}_{1 b}$ : Anger has a same-way relationship with negative WOM \\ $\boldsymbol{H}_{1 c}:$ Anger has a positive impact on switching intention}

Similar to anger, frustration is defined as the feeling of uncertainty and insecurity, which stems from a sense of inability to fulfill needs (Roseman, 1991). Frustration originates from external situation factors. In other words, the customer believes that uncontrollable situations are the cause of stressful events/things. Therefore, frustration is a distinct emotion with anger (Roseman, 1991; Smith \& Bolton, 2002). The failures in providing service are often considered a depressing experience (Laros \& Steenkamp, 2005; Nyer, 2000) as this happens by the impact of events out of control (e.g., bad weather makes the plane unable to take off). The Cognitive Appraisal Theory (Folkman et al., 1986) affirms negative emotions (frustration) as the first step to promote consumers who have appropriate coping behaviors to eliminate their unpleasant feeling (Donoghue \& De Klerk, 2013; Lazarus \& Folkman, 1984).

When feeling frustrated, the customer is motivated to complain or share a negative experience with others or form a switching intention because these behaviors will help them feel more at ease (Mattila \& Ro, 2008; Ro, 2014). Similarly anger, previous results also show that frustration also has a positive impact on complaints, negative WOM, and switching intention (Bonifield \& Cole, 2007; Bougie et al., 2003; Grégoire \& Fisher, 2008). Therefore, this study proposed the following hypotheses:

$$
\begin{aligned}
& \boldsymbol{H}_{2 a}: \text { Frustration has a positive impact on the complaint } \\
& \boldsymbol{H}_{2 b}: \text { Frustration has a same-way relationship with } \\
& \text { negative WOM } \\
& \boldsymbol{H}_{2 c}: \text { Frustration has a positive impact on switching } \\
& \text { intention }
\end{aligned}
$$

Regrets appear when customers think that the cause of stressful events due to the fault of themself (Bonifield \& Cole, 2007). Therefore, regrets often are formed when the customer imagines that the current situation may be better if they choose other providers. In other words, regrets appear when customers compare real results with the potential alternative outcomes (Zeelenberg \& Pieters, 2007; Zeelenberg et al., 
1998). Customers who are dissatisfied with the quality of service will often switch to other service providers (Mano \& Oliver, 1993; Loveman, 1998) and looking for understanding from others (friends, family, colleagues) (Zeelenberg \& Pieters, 2004). They noted that consumers who have a high level of regret often request to "turn their choices" and they are inclined to participate in mediation negotiations to achieve what they want instead of performing retaliatory acts (e.g., complaints) (Bonifield \& Cole, 2007). Therefore, this study proposed the following hypotheses:

\section{$\boldsymbol{H}_{3 a}:$ Regret has a positive impact on negative WOM \\ $\boldsymbol{H}_{3 b}$ : Regret has a positive impact on switching intention}

\subsubsection{Control Variables}

Previous empirical research recommends that demographic variables have an impact on coping behaviors of the customer in stressful situations, and should be analyzed in emotional studies (Gelbrich, 2009; Grégoire \& Fisher, 2008; Mattila \& Ro, 2008; Susskind, 2016). Therefore, the study investigates the impact of two demographic variables, including gender and marital status, on three types of coping behaviors: complaints, negative WOM, and switching intention. The study model was suggested by the author as follows:

\section{Data Collection and Methodology}

\subsection{The Scale}

The study model consists of six research concepts. The scale of all concepts is inherited from previous studies. The scale uses 5-point Likert scale, from (1) Strongly disagree to (5) Strongly agree. More specifically, three types of negative emotions include regret, anger, and frustration measured in turn by six, three, and four questions, respectively, are inherited from Bonifield and Cole (2007), Bougie et al. (2003), and Tronvoll (2011). Coping behavior, complaint, and switching intention are measured in by four and eight questions inherited from Bougie et al. (2003). Negative WOM is measured in three questions inherited from the study of Zeelenberg and Pieters (2004). Constructs and items are shown in Table 2.

\subsection{Data Collection Procedure and Methodology}

Samples are passengers who have experienced a near airline service failure (i.e., in less than three months before the date of the sample collection). The survey is conducted with different groups of passengers across gender, marital status, and airline company at Tan Son Nhat Airport, Ho Chi Minh City, Vietnam. The author is a lecturer at the University of Finance - Marketing, so it is convenient to collect the data at Tan Son Nhat Airport. The author and thirty 3rd-year trained students (11 male and 19 female students) of the Faculty of Business Administration participated as part of their course requirements. Participants were encouraged to re-experience their negative service experience step-by-step, complete the questionnaire, and give it back to the interviewer. We invited 650 passengers who have experienced delay departure time to participate in the study. 587 passengers responded, which represents a 90.3 percentage. Features of the collected samples are described in Table 1, and all of 587 passengers responses are used for further analysis by the SmartPLS software.

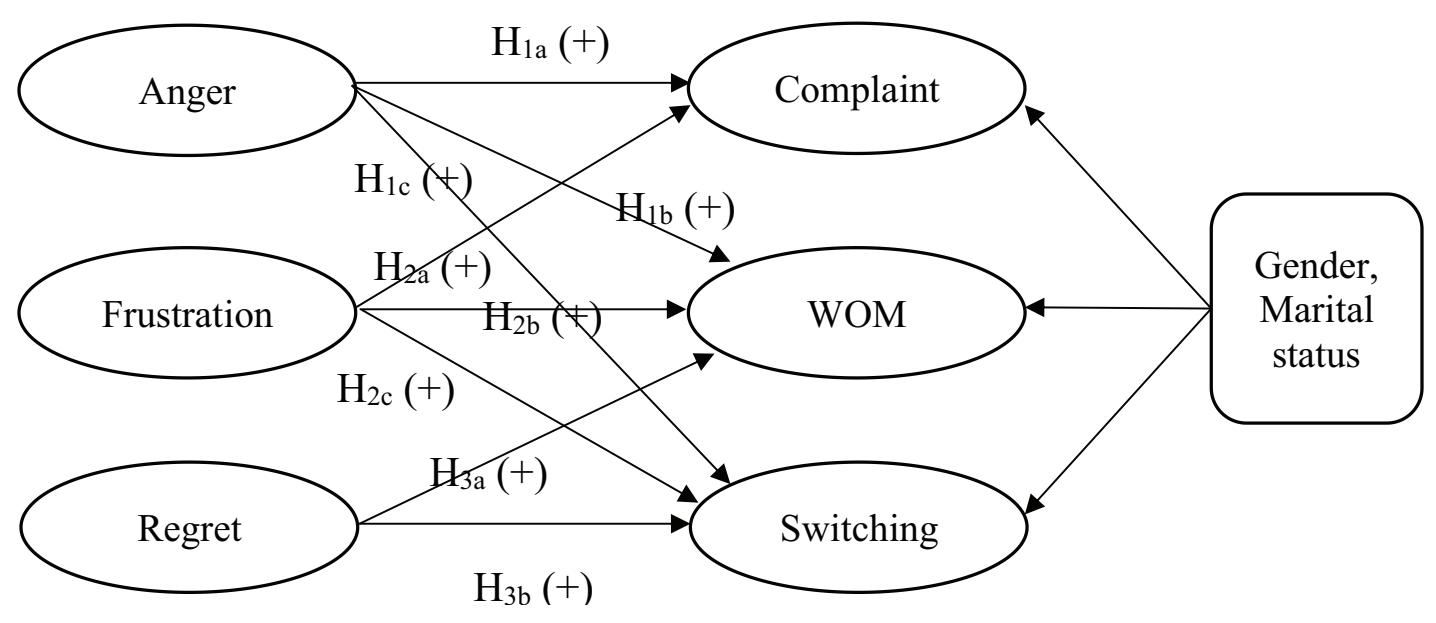

Figure 1: Proposed Research Model 
Table 1: Sample descriptive statistics.

\begin{tabular}{|l|l|c|c|}
\hline \multicolumn{2}{|l|}{ Characteristics } & Frequency & Percentage (\%) \\
\hline \multirow{3}{*}{ Gender } & Male & 219 & 37.31 \\
\cline { 2 - 4 } & Female & 368 & 62.69 \\
\hline \multirow{4}{*}{ Marital status } & Un-married & 256 & 43.61 \\
\cline { 2 - 4 } & Married & 331 & 56.39 \\
\hline \multirow{4}{*}{ Airlines company } & Vietnam Airline & 25 & 4.27 \\
\cline { 2 - 4 } & VietJet Air & 235 & 40.03 \\
\cline { 2 - 4 } & Jetstar Pacific & 168 & 28.62 \\
\cline { 2 - 4 } & Bamboo Airline & 159 & 27.08 \\
\hline
\end{tabular}

Table 2: Results of outer loading, reliability, and validity

\begin{tabular}{|c|c|c|c|c|}
\hline Items & $\begin{array}{c}\text { Outer } \\
\text { Loading }\end{array}$ & CA & CR & AVE \\
\hline Anger & & 0.689 & 0.828 & 0.616 \\
\hline I would feel angry about my experience at this airline company & 0.761 & & & \\
\hline I would feel very displeased with the service at this airline company & 0.752 & & & \\
\hline The more I think about it, the more hostile I would feel towards the company & 0.839 & & & \\
\hline Frustration & & 0.728 & 0.830 & 0.549 \\
\hline I can't bear disturbing feelings & 0.728 & & & \\
\hline I can't stand situations where I might feel upset & 0.757 & & & \\
\hline I can't stand to lose control of my feelings & 0.711 & & & \\
\hline I can't bear to feel that I am losing my mind & 0.768 & & & \\
\hline Regret & & 0.808 & 0.867 & 0.565 \\
\hline I would regret choosing the airline company that I chose & 0.733 & & & \\
\hline I would feel bad about ordering the service of this airline company & 0.756 & & & \\
\hline $\begin{array}{l}\text { In retrospect, I would feel that I could have made a better choice by choosing a } \\
\text { different company }\end{array}$ & 0.747 & & & \\
\hline I would feel sorry for choosing this airline company & 0.783 & & & \\
\hline $\begin{array}{l}\text { I would feel that if I could do it all over, I would choose a different airline } \\
\text { company }\end{array}$ & 0.739 & & & \\
\hline Complaint & & 0.730 & 0.847 & 0.649 \\
\hline I will complain about the quality of service to the manager & 0.800 & & & \\
\hline I will request the manager to make a solution & $\left({ }^{*}\right)$ & & & \\
\hline I will discuss the problem with the manager & 0.823 & & & \\
\hline $\begin{array}{l}\text { I will inform the company about the problem so that they will able to do better in } \\
\text { the future }\end{array}$ & 0.793 & & & \\
\hline WOM & & 0.729 & 0.847 & 0.648 \\
\hline I will speak to my friends about my bad experience & 0.805 & & & \\
\hline I will tell my relatives never to use the service of this airline company & 0.816 & & & \\
\hline I will convince my colleagues not to do business with the airline company & 0.794 & & & \\
\hline Switching Intention & & 0.824 & 0.877 & 0.587 \\
\hline I do not like this airline company & 0.736 & & & \\
\hline I would not continue to use the service of this airline company & 0.772 & & & \\
\hline I intend to switch to another airline company & 0.785 & & & \\
\hline I would not choose this airline company next time & 0.795 & & & \\
\hline I shall need the services of another airline company & 0.744 & & & \\
\hline
\end{tabular}

Note: CA: Cronbach's Alpha; CR: Composite Reliability; AVE: Average Variance Extracted; and (*): rejected questions. 


\section{Empirical Results and Discussion}

\subsection{Empirical results}

\subsubsection{Reliability and Validity Test}

In this study, we followed the suggestion of Hair et al. (2016) to test the reliability and validity scale. The reliability and discriminant of the scale is checked by the Composite Reliability (CR) and the Average Variance Extracted (AVE).

Next, we applied the Heterotrait-Monotrait Ratio (HTMT) to detect discriminant validity reliably. According to Hair et al. (2016), if the HTMT values are less than the thresholds of 0.85 , it implies all constructs in this research have discriminant validity. The values of HTMT for all pairs of variables are shown in Table 3 .

According to Table 2 and Table 3, all scales are reliable $(\mathrm{CR}>0.6, \mathrm{AVE}>0.5)$ (Fornell \& Larcker, 1981). At the same time, the outer loading coefficient is greater than 0.7 , and the HTMT values are less than 0.85 . Hence, all scales accomplish reliability and discriminant validity (Nunnally \& Bernstein, 1994).

\subsubsection{Assessment of PLS-SEM Structural Model Results}

The indicators to assess the quality of the PLS-SEM models and hypothesis testing are based on the suggestions of Hair et al. $(2016,2017)$. According to these authors, there is not a general measure suitable for the PLS-SEM model. Instead, the quality of the model is measured through two values, $\mathrm{R}^{2}$ and $\mathrm{Q}^{2}$. Firstly, the research assesses collinearity for all variables in the study. The VIF indicators of all variables are less than 2.0. It implies that collinearity is not an essential error in the study. Secondly, the research examines the $\mathrm{R}^{2}$ value of the endogenous latent variables. Following the rules of thumb, the $\mathrm{R}^{2}$ value of complaint is 0.481 , negative WOM is 0.462 , whereas the $R^{2}$ value of switching intention (0.436) considers moderate. According to the results in Table 4 , the $\mathrm{f}^{2}$ values for all combinations of exogenous constructs are medium. That means Anger/ Frustration/Regret has a moderate effect on the complaint or negative WOM or switching intention. Stone-Geisser indicator suggested checking the $\mathrm{Q}^{2}$ value, an indicator of predictive power beyond the model of the model, or the level of predictability. In table 4 , the $\mathrm{Q}^{2}$ values of all two endogenous constructs are considerably above zero.

As expected, the results of the path-relationship analysis show that there is a positive impact of three negative emotions on coping behaviors at the level of $1 \%$ significant. As such, it is possible to conclude the hypotheses $\mathrm{H}_{1}$ to $\mathrm{H}_{3}$ is supported in the study.

The test results show that anger has the strongest impact on the complaint $(\beta=0.510)$, while the frustration has the most powerful impact on the WOM $(\beta=0.372)$. Anger also has a strong impact on the switching intention $(\beta=$ $0.419)$ and the WOM $(\beta=0.161)$. Besides, frustration is an important subject of the complaint $(\beta=0.271)$ and the switching intention $(\beta=0.147)$. The results also show regret that positively impacts the WOM $(\beta=0.253)$ stronger than the switching intention $(\beta=0.19)$. Finally, the negative emotional variables explained $48.1 \%$ of the volatility of the complaint variable, $46.2 \%$ the volatility of the WOM variable, and $43.6 \%$ the volatility of the switching intention variable. Among control variables, there is no statistical evidence to conclude that gender or marital status have an impact on coping behavior.

\subsection{Discussion}

The Cognitive Appraisal theory indicates that stressful situations will produce negative emotions, thereby encouraging coping behaviors. In the service sector, previous studies confirm that coping behaviors often aroused negative emotions due to customer desire to minimize stress and increase emotional states in favor of themselves (Bonifield \& Cole, 2007; Bougie et al., 2003; Donoghue \& De Klerk, 2013). Therefore, the research results are in line with the theoretical literature and previous studies. However, different negative emotions will form various coping behaviors (Bougie et al., 2003; Donoghue \& De Klerk, 2013). Therefore, while anger and frustration are assumed to have an impact on all three types of coping behaviors, including the complaint, negative WOM, and switching intention, regret is assumed to have an impact on negative WOM and switching intention.

Table 3: HTMT value for discriminant validity

\begin{tabular}{|l|c|c|c|c|c|c|}
\hline \multicolumn{1}{|c|}{ Construct } & (1) & (2) & (3) & (4) & (5) & (6) \\
\hline Anger (1) & 0.785 & & & & & \\
\hline Frustration (2) & 0.529 & 0.741 & & & & \\
\hline Regret (3) & 0.646 & 0.618 & 0.752 & & & \\
\hline Complaint (4) & 0.653 & 0.540 & 0.657 & 0.805 & & \\
\hline WOM (5) & 0.521 & 0.615 & 0.586 & 0.520 & 0.805 & 0.766 \\
\hline Switching (6) & 0.619 & 0.487 & 0.553 & 0.577 & 0.487 & 0.7 \\
\hline
\end{tabular}


Table 4: Result of the structural model

\begin{tabular}{|c|c|c|c|c|c|}
\hline Relationship & & $\beta$ & Std.Error & t-value & Conclusion \\
\hline Anger $\rightarrow$ Complaint & $\mathrm{H}_{1 \mathrm{a}}$ & 0.510 & 0.043 & $11.81^{* \star *}$ & Support \\
\hline Anger $\rightarrow$ WOM & $\mathrm{H}_{1 \mathrm{~b}}$ & 0.161 & 0.044 & $3.692^{\star * *}$ & Support \\
\hline Anger $\rightarrow$ Switching & $\mathrm{H}_{1 \mathrm{c}}$ & 0.419 & 0.044 & $9.537^{* * *}$ & Support \\
\hline Frustration $\rightarrow$ Complaint & $\mathrm{H}_{2 \mathrm{a}}$ & 0.271 & 0.048 & $5.651^{* * *}$ & Support \\
\hline Frustration $\rightarrow$ WOM & $\mathrm{H}_{2 \mathrm{~b}}$ & 0.372 & 0.042 & $8.776^{\star * *}$ & Support \\
\hline Frustration $\rightarrow$ Switching & $\mathrm{H}_{2 \mathrm{c}}$ & 0.147 & 0.051 & $2.861^{* *}$ & Support \\
\hline Regret $\rightarrow$ WOM & $\mathrm{H}_{3 \mathrm{a}}$ & 0.253 & 0.053 & $4.764^{* * *}$ & Support \\
\hline Regret $\rightarrow$ Switching & $\mathrm{H}_{3 \mathrm{~b}}$ & 0.190 & 0.048 & $3.981^{* * *}$ & Support \\
\hline $\mathrm{R}^{2}$ value & \multicolumn{5}{|c|}{$\mathrm{R}^{2}($ Complaint $)=0.481 ; \mathrm{WOM}=0.462 ;$ Switching $=0.436$} \\
\hline \multirow[t]{4}{*}{$f^{2}$ value } & \multicolumn{5}{|c|}{$\mathrm{f}^{2}($ Anger $\rightarrow$ Complaint $)=0.361 ;($ Anger $\rightarrow$ WOM $)=0.027$} \\
\hline & \multicolumn{5}{|c|}{$f^{2}($ Anger $\rightarrow$ Switching $)=0.174 ;($ Frustration $\rightarrow$ Complaint $)=0.102$} \\
\hline & \multicolumn{5}{|c|}{$\mathrm{f}^{2}($ Frustration $\rightarrow$ WOM $)=0.151 ;($ Frustration $\rightarrow$ Switching $)=0.023$} \\
\hline & \multicolumn{5}{|c|}{$\mathrm{f}^{2}($ Regret $\rightarrow \mathrm{WOM})=0.057 ;($ Regret $\rightarrow$ Switching $)=0.031$} \\
\hline$Q^{2}$ value & \multicolumn{5}{|c|}{$\mathrm{Q}^{2}($ Complaint $)=0.326 ; \mathrm{Q}^{2}(\mathrm{WOM})=0.278 ; \mathrm{Q}^{2}($ Switching $)=0.239$} \\
\hline
\end{tabular}

Note: ${ }^{*} p<0.05,{ }^{* *} p<0.01,{ }^{* * *} p<0.001$

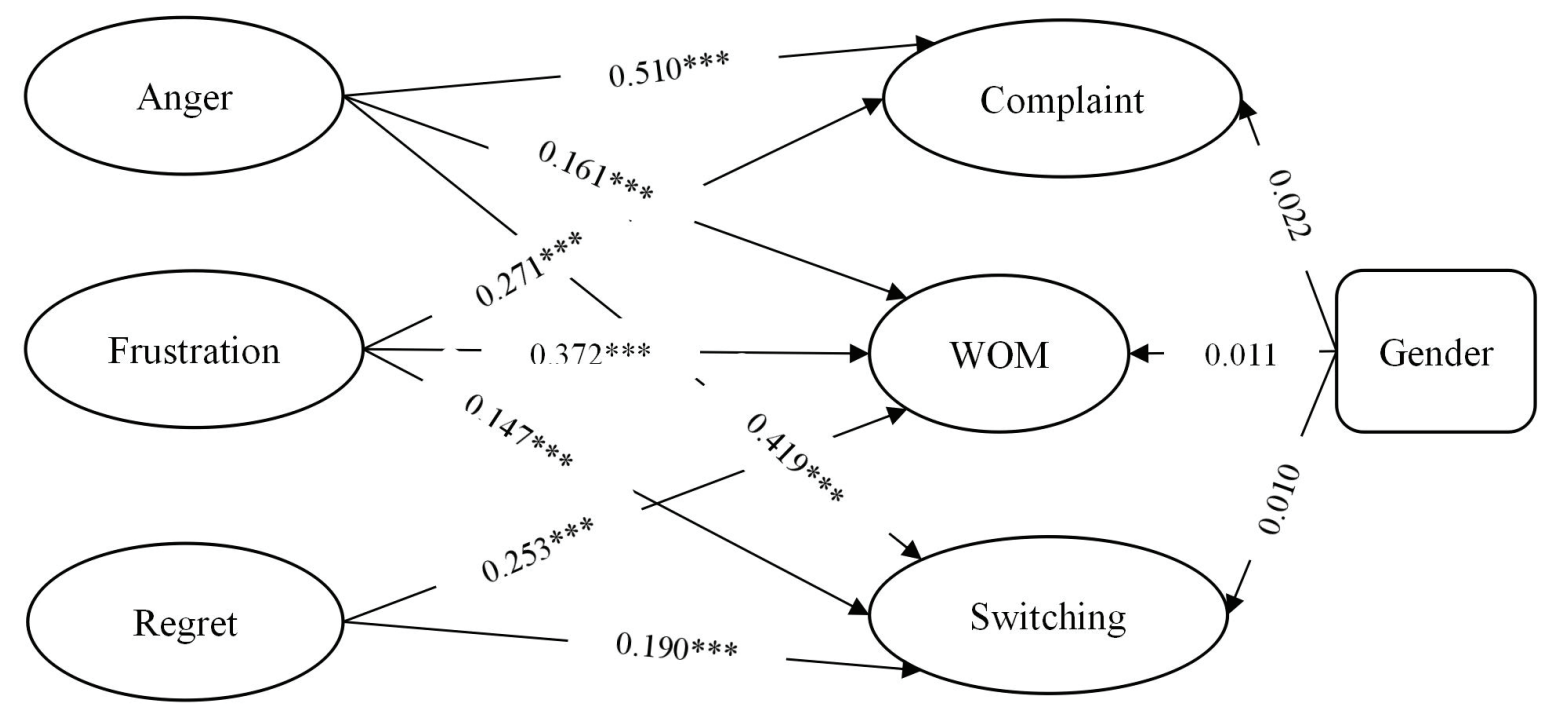

Figure 2: Results of path-relationship analysis

Psychological studies show that an individual's anger promotes retaliatory behavior, as they identify the subject responsible for stressful situations (Grégoire \& Fisher, 2008). Therefore, the results of studies have similarities with previous studies in the service sector. Similarly, anger and frustration has the same-way relationship with coping behavior, especially the switching intention (Bonifield \& Cole, 2007; Bougie et al., 2003; Grégoire \& Fisher, 2008).
Because these acts help the individual to feel more at ease (Mattila \& Ro, 2008; Ro, 2014). Finally, the impact of regret on negative WOM and switching intention was confirmed in previous studies (Zeelenberg \& Pieters, 2004). The research suggests that customers with a sense of regret will be inclined to implement a sweet solution to achieve what is desired rather than performing retaliation. Therefore, they will not complain to the service provider (Bonifield \& Cole, 2007). 


\section{Conclusion and Administrative Implications}

\subsection{Conclusion}

This research aims to investigate the impact of negative emotions on coping behaviors of the passenger using airline services at Tan Son Nhat Airport, Ho Chi Minh City, Vietnam. Accordingly, three types of negative emotions triggered by the failure in providing airline services, include: anger, frustration, and regret, that are assumed to impact three types of coping behaviors of customers, which include the complaint, negative WOM, and switching intention. As expected, negative emotions have a positive impact on coping behaviors. More specifically, anger and frustration impact all three coping behaviors: complaints, negative WOM, and switching intention, while regrets have an impact on negative WOM and switching intention. So, the research has essential contributions to academic and practical.

\subsection{Administrative Implications}

The goals of the airline company are to limit the negative emotions of passengers, thereby limit the coping behaviors. By understanding coping behaviors, the manager can minimize the retaliation and choose a suitable mediation. All three negative emotions have a strong impact on switching intention. This is the most serious behavior for the airline company because they may be losing passenger loyalty. Also, these variables have an impact on negative WOM. This behavior can affect the image and reputation of the airline company. The complaint has a weak effect on service providers because the airline company has a chance to compensate and provide remedial care to passengers.

To reduce these negative emotions, the airline company needs to adopt a retrospective explanation. This information helps passengers put them in an airline company's position so that they can understand the reason for service failure. Furthermore, this explanation also helps reduce the desire for the responsibility of an airline company (Weiner, 2000). Therefore, anger, frustration, and regret to be appeased, and coping behavior (complaints, negative WOM, switching intention) will seldom occur. However, it should avoid denying the liability of the airline company or blame third parties (Davidow, 2003). On the other hand, the airline company needs to train staff on how to handle situations in which passengers are unhappy with the company's service (Bonifield \& Cole, 2007).

\section{References}

Bagozzi, R., Gurhan-Canli, Z., \& Priester, J. (2002). The social psychology of consumer behavior. New York, NY: McGrawHill Education.
Bagozzi, R. P., Gopinath, M., \& Nyer, P. U. (1999). The role of emotions in marketing. Journal of the Academy of Marketing Science, 27(2), 184-206.

Bonifield, C., \& Cole, C. (2007). Affective responses to service failure: Anger, regret, and retaliatory versus conciliatory responses. Marketing Letters, 18(1-2), 85-99.

Bougie, R., Pieters, R., \& Zeelenberg, M. (2003). Angry customers don't come back, they get back: The experience and behavioral implications of anger and dissatisfaction in services. Journal of the Academy of Marketing Science, 31(4), 377-393.

Costa, P. T., \& McCrae, R. R. (1992). Four ways five factors are basic. Personality and Individual Differences, 13(6), 653-665.

Davidow, M. (2003). Organizational responses to customer complaints: What works and what doesn't. Journal of Service Research, 5(3), 225-250.

Donoghue, S., \& de Klerk, H. M. (2013). Consumers' anger and coping behaviors following appraisals of appliance failure. International Journal of Consumer Studies, 37(2), 214-221.

Folkman, S., Lazarus, R. S., Dunkel-Schetter, C., DeLongis, A., \& Gruen, R. J. (1986). Dynamics of a stressful encounter: Cognitive appraisal, coping, and encounter outcomes. Journal of Personality and Social Psychology, 50(5), 992-1003.

Gao, J., \& Kerstetter, D. L. (2018). From sad to happy to happier: Emotion regulation strategies used during a vacation. Annals of Tourism Research, 69, 1-14.

Gelbrich, K. (2009). Anger, frustration, and helplessness after service failure: Coping behaviors and effective informational support. Journal of the Academy of Marketing Science, 38(5), 567-585.

Grégoire, Y., \& Fisher, R. J. (2008). Customer betrayal and retaliation: when your best customers become your worst enemies. Journal of the Academy of Marketing Science, 36(2), 247-261.

Hair, J., Sarstedt, M., Hopkins, L., \& Kuppelwieser, V. (2014). Partial least squares structural equation modeling (PLS-SEM): An emerging tool in business research. European Business Review, 26(2), 106-121.

Hair, J. F., Hult, G. T. M., Ringle, C., \& Sarstedt, M. (2016). A primer on partial least squares structural equation modeling (PLS-SEM). Los Angeles, CA: Sage Publications.

Hair, J. F., Sarstedt, M., Ringle, C. M., \& Gudergan, S. P. (2017). Advanced Issues in Partial Least Squares Structural Equation Modeling. Los Angeles, CA: Sage Publications.

Han, W. H. (2020). Consumers' Abductive Inference Error as Cognitive Impairment. Journal of Asian Finance, Economics and Business, 7(8), 747-752. https://doi.org/10.13106/jafeb.2020. vol7.no8.747

Hansen, H., M. Samuelsen, B., \& E. Sallis, J. (2013). The moderating effects of need for cognition on drivers of customer loyalty. European Journal of Marketing, 47(8), 1157-1176.

Hoang, C. C., \& Ngoc, B. H. (2019). The Relationship between Innovation Capability and Firm's Performance in Electronic 
Companies, Vietnam. Journal of Asian Finance, Economics and Business, 6(3), 295-304. https://doi.org/10.13106/jafeb.2019. vol6.no3.295

Jani, D., \& Han, H. (2015). Influence of environmental stimuli on hotel customer emotional loyalty response: Testing the moderating effect of the big five personality factors. International Journal of Hospitality Management, 44, 48-57.

Kalamas, M., Laroche, M., \& Makdessian, L. (2008). Reaching the boiling point: Consumers' negative affective reactions to company-attributed service failures. Journal of Business Research, 61(8), 813-824.

Khoa, B.T. (2020). The Antecedents of Relationship Marketing and Customer Loyalty: A Case of the Designed Fashion Product. Journal of Asian Finance, Economics and Business, 7(2), 195204. https://doi.org/10.13106/jafeb.2020.vol7.no2.195

Lai, L. H., Liu, C. T., \& Lin, J. T. (2011). The moderating effects of switching costs and inertia on the customer satisfactionretention link: Auto liability insurance service in Taiwan. Insurance Markets and Companies. Analyses and Actuarial Computations, 2(1), 69-78.

Laros, F. J. M., \& Steenkamp, J.-B. E. M. (2005). Emotions in consumer behavior: A hierarchical approach. Journal of Business Research, 58(10), 1437-1445.

Lazarus, R. S. (1991). Emotion and adaptation. Oxford, UK: Oxford University Press.

Lazarus, R. S., \& Folkman, S. (1984). Stress, appraisal, and coping. New York, NY: Springer.

Loveman, G. W. (1998). Employee satisfaction, customer loyalty, and financial performance: An empirical examination of the service profit chain in retail banking. Journal of Service Research, 1(1), 18-31.

Mano, H., \& Oliver, R. L. (1993). Assessing the dimensionality and structure of the consumption experience: Evaluation, feeling, and satisfaction. Journal of Consumer Research, 20(3), 451466.

Mathur, A., Moschis, G. P., \& Lee, E. (1999). Stress and consumer behavior. Journal of Marketing Practice: Applied Marketing Science, 5(6/7/8), 233-247.

Mattila, A. S., \& Enz, C. A. (2002). The role of emotions in service encounters. Journal of Service Research, 4(4), 268-277.

Mattila, A. S., \& Ro, H. (2008). Discrete negative emotions and customer dissatisfaction responses in a casual restaurant setting. Journal of Hospitality \& Tourism Research, 32(1), 89107.

Maute, M. F., \& Dubés, L. (1999). Patterns of emotional responses and behavioral consequences of dissatisfaction. Applied Psychology, 48(3), 349-366.

Nguyen, H. M., \& Khoa, B. T. (2019). The Relationship between the Perceived Mental Benefits, Online Trust, and Personal
Information Disclosure in Online Shopping. Journal of Asian Finance, Economics and Business, 6(4), 261-270. https://doi. org/10.13106/jafeb.2019.vol6.no4.261

Nyer, P. U. (2000). An investigation into whether complaining can cause increased consumer satisfaction. Journal of Consumer Marketing, 17(1), 9-19.

Nunnally, J. C., \& Bernstein, I. (1994). The assessment of reliability. Psychometric Theory, 3(1), 248-292.

Oliver, R. L. (2014). Satisfaction: A behavioral perspective on the consumer (2nd ed.). London, UK: Routledge.

Ringle, C. M., Sarstedt, M., \& Straub, D. W. (2012). Editor's comments: A critical look at the use of PLS-SEM in" MIS Quarterly". MIS Quarterly, 36(1), 3-14.

Ro, H. (2014). Customer dissatisfaction responses to restaurant service failures: Insights into noncomplainers from a relational perspective. Journal of Hospitality Marketing \& Management, 24(4), 435-456.

Roseman, I. J. (1991). Appraisal determinants of discrete emotions. Cognition \& Emotion, 5(3), 161-200.

Smith, A. K., \& Bolton, R. N. (2002). The effect of customers' emotional responses to service failures on their recovery effort evaluations and satisfaction judgments. Journal of the Academy of Marketing Science, 30(1), 5-23.

Stephens, N., \& Gwinner, K. P. (1998). Why don't some people complain? A cognitive-emotive process model of consumer complaint behavior. Journal of the Academy of Marketing Science, 26(3), 172-189.

Susskind, A. M. (2016). Consumer frustration in the customerserver exchange: The role of attitudes toward complaining and information inadequacy related to service failures. Journal of Hospitality \& Tourism Research, 28(1), 21-43.

Swan, J. E., \& Oliver, R. L. (1989). Postpurchase communications by consumers. Journal of Retailing, 65(4), 516-534.

Tronvoll, B. (2011). Negative emotions and their effect on customer complaint behavior. Journal of Service Management, 22(1), 111-134.

Walsh, G., Evanschitzky, H., \& Wunderlich, M. (2008). Identification and analysis of moderator variables. European Journal of Marketing, 42(9-10), 977-1004.

Watson, L., \& Spence, M. T. (2007). Causes and consequences of emotions on consumer behavior. European Journal of Marketing, 41(5-6), 487-511.

Weiner, B. (2000). Attributional thoughts about consumer behavior. Journal of Consumer Research, 27(3), 382-387.

Zeelenberg, M., \& Pieters, R. (2004). Beyond valence in customer dissatisfaction. Journal of Business Research, 57(4), 445-455. 
Zeelenberg, M., \& Pieters, R. (2007). A theory of regret regulation 1.0. Journal of Consumer Psychology, 17(1), 3-18.

Zeelenberg, M., van Dijk, W. W., SR Manstead, A., \& der Pligt, J. (1998). The experience of regret and disappointment. Cognition \& Emotion, 12(2), 221-230.
Zeithaml, V. A., Berry, L. L., \& Parasuraman, A. (1996). The behavioral consequences of service quality. Journal of Marketing, 60(2), 31-46.

Zourrig, H., Chebat, J.-C., \& Toffoli, R. (2009). Consumer revenge behavior: A cross-cultural perspective. Journal of Business Research, 62(10), 995-1001. 